\title{
Development of a Model for Estimating Stomatal Conductance of Maize Leaves
}

\author{
Gui-Rui YU and Keiichi NAKAYAMA \\ (Faculty of Horticulture, Chiba University, 648 Matsudo, Matsudo-city, Chiba, 271 Japan)
}

\begin{abstract}
Based on a study of the characteristics of the stomatal response to environmental factors, a new environmental variable model for estimating stomatal conductance over a long time period was developed. This model was based on multiplying the potential stomatal conductance by the relative degree of stomatal opening during daytime. The estimated precision of this model was quite high.

Key words: Environmental variable model, Maize, Stomatal conductance.
\end{abstract}

\section{Introduction}

Developing a model for estimating stomatal conductance is very important because stomatal conductance is often used to explain fluxes of $\mathrm{CO}_{2}$ and water vapor between plant and atmosphere. Jarvis (1976) took each environmental factor which influences stomatal conductance as an independent response function, and proposed an environmental variable model that combined these response functions (now called Jarvis' model). At present, this model is widely used and has become the prototype of most models.

The authors optimized Jarvis' model by using measurements made at a maize field in 1992-1994. As a result, in the case of a short time period of one year, a relatively high estimated precision was obtained with the two-variable model, but in a long time period of three years, the coefficient of determination of the model was only 0.45 , even if the model was constructed with four variables (Yu et al., 1996c). The variability of stomatal conductance and the characteristics of stomatal response to environmental variables over long-period scales have been examined (Yu et al., 1996a,b). Here, we attempt to develop a new environmental variable model based on the previous studies.

\section{Combination Model}

Under natural conditions, the opening and closing of stomata are mainly influenced by environmental factors such as sunlight, temperature, saturation deficit, water stress, $\mathrm{CO}_{2}$ concentration, etc. (Jarvis, 1976). When the photosynthetic photon flux density
$\left(Q_{\mathrm{p}}\right)$, leaf temperature $\left(T_{\mathrm{L}}\right)$, saturation deficit $\left(D_{\mathrm{e}}\right)$, leaf water potential $\left(\Psi_{\mathrm{L}}\right)$, etc. are used as the parameters of the environmental factors, Jarvis' model can be represented by

$$
G_{\mathrm{st}}=\operatorname{opt}\left\{\prod_{I}^{N} G\left(X_{I}\right)\right\}
$$

where $X=\left(X_{1}, \ldots, X_{\mathrm{I}} \ldots, X_{\mathrm{N}}\right) \in\left(Q_{\mathrm{p}}, D_{\mathrm{e}}, \Psi_{\mathrm{L}}, T_{\mathrm{L}}, \ldots\right)$ are environmental variables, $\mathrm{N}=1,2, \ldots$ are the number of variables in the models, and $\mathrm{I}=1,2, \ldots \mathrm{N}$ are the variable numbers. 'opt' means the optimization of the model. $G\left(X_{\mathrm{I}}\right) \in\left\{G_{\mathrm{i}}\left(Q_{\mathrm{p}}\right), g_{\mathrm{j}}\left(D_{\mathrm{c}}\right), \quad g_{\mathrm{q}}\left(\Psi_{\mathrm{L}}\right)\right.$, $\left.g_{\mathrm{k}}\left(T_{\mathrm{L}}\right), \ldots\right\}$ are the functions of each environmental variable influencing stomatal conductance.

For a long period scale, the stomatal conductance $\left(G_{\mathrm{st}}\right)$ is the influenced by both the relative degree of the stomatal opening $(R D O)$ and the potential conductance $\left(G_{\mathrm{Max}}\right)$ during daytime (Yu et al., 1996b). The $R D O$ depends on the relative variation of environmental variables, and $G_{\mathrm{Max}}$ is determined by the mean of the environmental variables during daytime. Therefore, the combination model for estimating the stomatal conductance can be represented by

$$
\begin{aligned}
G_{\mathrm{st}} & =G_{\mathrm{Max}} R D O \\
G_{\mathrm{Max}} & =\operatorname{opt}\left\{\prod_{I}^{N} G\left(X_{m, I}\right)\right\} \\
\mathrm{N} & =1,2,3, \ldots ; \mathrm{I}=1,2, \ldots, \mathrm{N} \\
R D O & =\operatorname{opt}\left\{\prod_{I}^{N} R\left(X_{R, I}\right)\right\} \\
\mathrm{N} & =1,2,3,4, \mathrm{I}=1,2, \ldots, \mathrm{N}
\end{aligned}
$$


where $X_{\mathrm{m}, \mathrm{I}}=\left(X_{\mathrm{m}, 1}, \ldots, X_{\mathrm{m}, \mathrm{I}}, \ldots, X_{\mathrm{m}, \mathrm{N}}\right)$ are the daytime means of each environmental variable, and $G\left(X_{\mathrm{m}, \mathrm{I}}\right)$ are the response functions of $G_{\mathrm{Max}}$ to $X_{\mathrm{m}, \mathrm{I}}$. $X_{\mathrm{R}, \mathrm{I}}=\left(X_{\mathrm{R}, 1}, \ldots, X_{\mathrm{R}, \mathrm{l}}, \ldots, X_{\mathrm{R}, \mathrm{N}}\right)$ are the relative variations of each environmental variable and $R\left(X_{\mathrm{R}, \mathrm{I}}\right)$ are the response functions of $R D O$ to $X_{\mathrm{R}, \mathrm{I}}$.

\section{Material and Methods}

\subsection{Experimental conditions}

The experiment was conducted at a maize (Zea mays L.) field at the Faculty of Horticulture, Chiba University during the summers of 1992-1994. The area of the field was about $20 \mathrm{~m} \times 20 \mathrm{~m}$ and the soil was volcanic ash. The planting density varied from 31300 to 35700 plants per hectare depending on the year. The row spacing was $70-80 \mathrm{~cm}$ and the intrarow spacing was $40 \mathrm{~cm}$. The growth period was from about the first ten days of June to the end of August. 1992 was an average year, 1993 was a rainy year with a cool summer, and 1994 was a megathermal and drought year (cf. Yu et al., 1996a).

\subsection{Collection of data}

Stomatal resistance was measured every hour from 5:30 to $18: 30$ on two specified plants with a porometer (LI-1600, Li-Cor) under natural conditions in the field. The measured positions were at the center on the adaxial and abaxial surfaces of each leaf at three positions, separately, i.e. at the upper (from the top of stem the 2nd, 3rd), middle (the 5,6 th) and lower part (the 8,9th) on the stem. The stomatal conductance $\left(G_{\mathrm{st}}, \mathrm{cm} \mathrm{s}^{-1}\right)$ to both sides was calculated by

$$
G_{\text {st }}=1 / r_{\text {std }}+1 / r_{\text {stb }}
$$

where $r_{\text {std }}$ and $r_{\text {stb }}$ are the stomatal resistances (s $\mathrm{cm}^{-1}$ ) on the adaxial and abaxial surfaces, separately.

The photosynthetic photon flux density $\left(Q_{\mathrm{p}}, \mu \mathrm{mol}\right.$ $\left.\mathrm{m}^{-2} \mathrm{~s}^{-1}\right)$, leaf temperature $\left(T_{\mathrm{L}},{ }^{\circ} \mathrm{C}\right)$ and saturation deficit $\left(D_{\mathrm{e}}, \mathrm{hPa}\right)$ were also measured by sensors attached to the porometer at the time the stomatal resistance was measured. The measurement of water potential ( $\Psi_{\mathrm{L}}, \mathrm{MPa}$ ) used a pressure chamber at two plants near the plants used for measuring stomatal resistance.

\subsection{Adaptation and evaluation of the model}

To analyze the characteristics of the mean stomatal response in the crop community, the mean values of $G_{\text {st }}$ at various leaf positions and the environmental factors in the community were used. For adapting the model, the parameters were calculated by the linear or non-linear minimum squares method and the adaptation of the model was evaluated by the coefficient of determination $\left(R^{2}\right)$ and the estimated error of mode $(\mathrm{Se})$.

\section{Results and Discussion}

\subsection{Model for estimating $G_{\text {Max }}$}

It was found that $G_{\text {Max }}$ was influenced by the daytime mean water potential $\left(\Psi_{L, \mathrm{~m}}\right)$, saturation deficit $\left(D_{\mathrm{e}, \mathrm{m}}\right)$ and leaf temperature $\left(T_{\mathrm{L}, \mathrm{m}}\right)$ based on the results of an analysis of response characteristics of $G_{\text {Max }}$ to environmental variables (Yu et al., 1996b). Therefore, the model of equation (2.2) for estimating $G_{\text {Max }}$ can be determined by

$$
G_{\mathrm{Max}}=\operatorname{opt}\left\{G_{\mathrm{j}}\left(D_{e, \mathrm{~m}}\right) G_{\mathrm{q}}\left(\Psi_{\mathrm{L}, \mathrm{m}}\right) G_{\mathrm{k}}\left(T_{\mathrm{L}, \mathrm{m}}\right)\right\}
$$

where a lot of expressions of $G_{\mathrm{j}}\left(D_{\mathrm{e}, \mathrm{m}}\right), G_{\mathrm{q}}\left(\Psi_{\mathrm{L}, \mathrm{m}}\right)$, $G_{\mathrm{k}}\left(T_{\mathrm{L}, \mathrm{m}}\right)$ are included in the model. To simplify, we used the following functions:

$$
\begin{aligned}
& G_{\mathrm{j}}\left(D_{\mathrm{e}, \mathrm{m}}\right) \\
& G_{1}\left(D_{\mathrm{m}}\right)=\mathrm{b}_{1}-\mathrm{b}_{2} D_{\mathrm{e}, \mathrm{m}} ; \\
& R^{2}=0.349 \\
& G_{2}\left(D_{\mathrm{m}}\right)=1 /\left(\mathrm{b}_{1}+\mathrm{b}_{2} D_{\mathrm{e}, \mathrm{m}}\right) \text {; } \\
& R^{2}=0.408 \\
& G_{3}\left(D_{\mathrm{m}}\right)=1 /\left(1-\mathrm{b}_{1} D_{\mathrm{e}, \mathrm{m}}^{\mathrm{b} 2}\right) \text {; } \\
& R^{2}=0.328 \\
& G_{\mathrm{q}}\left(\Psi_{\mathrm{L}, \mathrm{m}}\right) \\
& G_{1}\left(\Psi_{\mathrm{m}}\right)=\mathrm{c}_{1}+\mathrm{c}_{2} \Psi_{\mathrm{L}, \mathrm{m}} ; \quad R^{2}=0.761 \\
& G_{2}\left(\Psi_{\mathrm{m}}\right)=\mathrm{G}_{\mathrm{M}^{-}}-\mathrm{c}_{1} \exp \left(-\mathrm{c}_{2} \Psi_{\mathrm{L}, \mathrm{m}}\right) ; \quad R^{2}=0.224 \\
& G_{3}\left(\Psi_{\mathrm{m}}\right)=G_{\mathrm{M}} /\left(1+\mathrm{c}_{1}\left(-\Psi_{\mathrm{L}, \mathrm{m}}\right)^{\mathrm{c} 2}\right) ; \quad R^{2}=0.815 \\
& G_{\mathrm{k}}\left(T_{\mathrm{L}, \mathrm{m}}\right) \\
& G_{1}\left(T_{\mathrm{m}}\right)=\mathrm{d}+\mathrm{d}_{1} T_{\mathrm{L}, \mathrm{m}}+\mathrm{d}_{2} T_{\mathrm{L}, \mathrm{m}}{ }^{2} ; \quad R^{2}=0.514 \\
& G_{2}\left(T_{m}\right)=G_{M}\left[\frac{T_{L, m}-T_{l}}{T_{o}-T_{l}}\right]\left[\frac{T_{h}-T_{L, m}}{T_{h}-T_{o}}\right]^{\alpha} ; R^{2}=0.574 \\
& \alpha=\left(T_{\mathrm{h}}-T_{\mathrm{l}}\right) /\left(T_{\mathrm{o}}-T_{\mathrm{l}}\right)
\end{aligned}
$$

where $G_{\mathrm{M}}$ is the maximum ( $\mathrm{cm} \mathrm{s}^{-1}$ ) of $G_{\mathrm{Max}}$, and $\mathrm{b}_{1}$ and $b_{2}, c_{1}$ and $c_{2}, d$ and $d_{1}, d_{2}$ are constants for each function. $T_{\mathrm{l}}, T_{\mathrm{o}}$ and $T_{\mathrm{h}}$ are the lower limit, upper limit and optimal leaf temperature $\left({ }^{\circ} \mathrm{C}\right)$ for opening of the stomata. 
By comparing $R^{2}$ of the regression formula of these functions, we found that the strongest factor influencing $G_{\mathrm{Max}}$ was the leaf water potential. After optimizing the three-variable model of equation (4), the following optimal model is obtained.

$$
G_{\mathrm{Max}}=\frac{d_{0}+d_{1} T_{L, m}+d_{2} T_{L, m}{ }^{2}}{\left(b_{1}+b_{2} D_{e, m}\right)\left(1+c_{1}\left(-\psi_{L, m}\right)^{c 2}\right)}
$$

where $b_{1}=0.702, b_{2}=0.073, c_{1}=8.269, c_{2}=4.033, d_{0}=-$ $3.763, \mathrm{~d}_{1}=0.515$ and $\mathrm{d}_{2}=0.0144$ are the constants. The estimated precision of this model was quite high (Fig. 1).

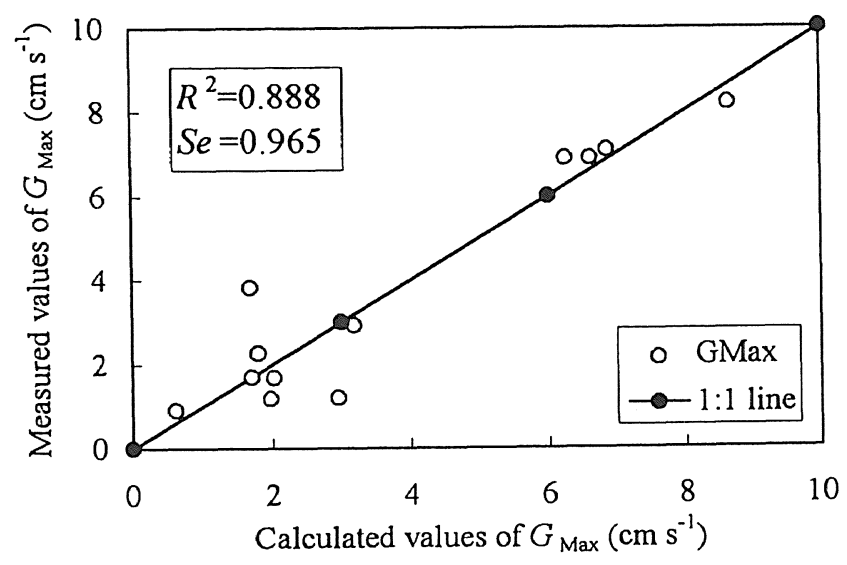

Fig. 1 Relationship between the measured value and the estimated value of $G_{\mathrm{Max}}$ by the model based equation (5).

\subsection{Model for estimating $R D O$}

If the difference of the response curves in the two processes of stomatal opening and closing is ignored, the response functions of $R D O$ to four variables are expressed by the formulas (1)-(4).

$$
\begin{array}{ll}
R\left(Q_{\mathrm{p}}\right)=\mathrm{A}_{1}+\mathrm{A}_{2} Q_{\mathrm{p}} / Q_{\mathrm{p}, \mathrm{Max}} ; & R^{2}=0.757 \\
R\left(D_{\mathrm{e}}\right)=\mathrm{B}_{1} \exp \left(\mathrm{B}_{2} D_{\mathrm{e}} / D_{\mathrm{e}, \mathrm{Max}}\right) ; & R^{2}=0.414 \\
R\left(\Psi_{\mathrm{L}}\right)=\mathrm{C}_{1} \exp \left(\mathrm{C}_{2} \Psi_{\mathrm{L}} / \Psi_{\mathrm{L}, \mathrm{Min}}\right) ; & R^{2}=0.389 \\
R\left(T_{\mathrm{L}}\right)=\mathrm{D}_{1} \exp \left(\mathrm{D}_{2} T_{\mathrm{L}} / T_{\mathrm{L}, \mathrm{Max}}\right) ; & R^{2}=0.519
\end{array}
$$

where $Q_{\mathrm{p}} / Q_{\mathrm{p}, \mathrm{Max}}, D_{\mathrm{e}} / D_{\mathrm{e}, \mathrm{Max}}, T_{\mathrm{L}} / T_{\mathrm{L}, \mathrm{Max}}, \Psi_{\mathrm{L}} / \Psi_{\mathrm{L}, \mathrm{Min}}$ are the relative variations of the environmental variables with 151 samples.

When the two processes of stomatal opening and closing were separated, the opening curve $\left(R_{\mathrm{o}}\left(D_{\mathrm{e}}\right)\right.$ and $\left.R_{\mathrm{o}}\left(T_{\mathrm{L}}\right)\right)$ and closing curve $\left(R_{\mathrm{c}}\left(D_{\mathrm{c}}\right)\right.$ and $\left.R_{\mathrm{c}}\left(T_{\mathrm{L}}\right)\right)$ are expressed by formulas (5) and (7), (6) and (8).

$$
\begin{aligned}
& R_{\mathrm{o}}\left(D_{\mathrm{e}}\right)=\mathrm{B}_{\mathrm{o} 1}+\mathrm{B}_{\mathrm{o} 2} D_{\mathrm{e}} / D_{\mathrm{e}, \mathrm{Max}} ; \quad R^{2}=0.704 \\
& R_{\mathrm{c}}\left(D_{\mathrm{e}}\right)=\mathrm{B}_{\mathrm{c} 1} \exp \left(\mathrm{B}_{\mathrm{c} 2} D_{\mathrm{e}} / \mathrm{D}_{\mathrm{e}, \mathrm{Max}}\right) ; R^{2}=0.517 \\
& R_{\mathrm{o}}\left(T_{\mathrm{L}}\right)=\mathrm{D}_{\mathrm{o} 1}+\mathrm{D}_{\mathrm{o} 2} T_{\mathrm{L}} / T_{\mathrm{L}, \mathrm{Max}} ; \quad R^{2}=0.688 \\
& R_{\mathrm{c}}\left(\mathrm{T}_{\mathrm{L}}\right)=\mathrm{D}_{\mathrm{c} 1} \exp \left(\mathrm{D}_{\mathrm{c} 2} T_{\mathrm{L}} / T_{\mathrm{L}, \text { Max }}\right) ; R^{2}=0.719
\end{aligned}
$$

According to $R^{2}$, the confidence limit of the above formulas exceeded $99 \%$, in which $R^{2}$ of formula (1) was the highest. For $D_{\mathrm{e}}$, and $T_{\mathrm{L}}$, when the two processes of stomatal opening and closing were distinguished, the significances of the regression formulas were higher.

By the above-mentioned reasoning, if the difference between the two curves for opening and closing of stomata was neglected, $R\left(X_{\mathrm{R}, \mathrm{I}}\right)$ of the multi-variable model (2.3) of $R D O$ are expressed by formulas (1)-(4). $R\left(X_{\mathrm{R}, \mathrm{I}}\right)$ for the opening process of stomata are expressed by formulas (1), (3), (5), (7) and $R\left(X_{\mathrm{R}, \mathrm{I}}\right)$ for the closing process are expressed by formulas (1), (3), (6), (8). $R^{2}$ of these assembled $R D O$ models with from 1 to 4 variables is shown in Table 1.

Table 1 Coefficients of determination $\left(R^{2}\right)$ of the regression formulas to the multivariable model of $R D O$.

\begin{tabular}{lllll}
\hline \multicolumn{1}{c}{ Models } & $R_{1}{ }^{2}$ & $R_{2}{ }^{2}$ & $R_{\mathrm{o}}{ }^{2}$ & $R_{\mathrm{c}}{ }^{2}$ \\
\hline$R\left(Q_{\mathrm{p}}\right)$ & 0.757 & 0.757 \\
$R\left(Q_{\mathrm{p}}, D_{\mathrm{e}}\right)$ & 0.754 & 0.773 & 0.771 & 0.785 \\
$R\left(Q_{\mathrm{p}}, T_{\mathrm{L}}\right)$ & 0.753 & 0.783 & 0.751 & 0.783 \\
$R\left(Q_{\mathrm{p}}, D_{\mathrm{e}}, T_{\mathrm{L}}\right)$ & 0.744 & 0.767 & 0.732 & 0.787 \\
$R\left(Q_{\mathrm{p}}, D_{\mathrm{c}}, \Psi_{\mathrm{L}}, T_{\mathrm{L}}\right)$ & 0.743 & 0.768 & 0.732 & 0.789 \\
\hline \multicolumn{4}{l}{ Where $R_{1}{ }^{2}$ and ${R_{2}{ }^{2} \text { are the coefficients of }}^{\text {determination of curves without distinguishing }}$} \\
stomatal opening and closing and separating \\
them into two processes. $R_{\mathrm{o}}{ }^{2}$ and $R_{\mathrm{c}}{ }^{2}$ are the \\
coefficients of determination for the curves of \\
stomatal opening and closing.
\end{tabular}

According to Table 1 , the $R^{2}$ for $R D O$ models without distinguishing the two processes of the opening and closing, could not be improved by increasing the number of the input variables. It appears that the $R D O$ model is sufficiently expressed by

$$
R D O=R\left(Q_{\mathrm{p}}\right)=\mathrm{A}_{1}+\mathrm{A}_{2} Q_{\mathrm{p}} / Q_{\mathrm{p}, \operatorname{Max}}
$$

where $A_{1}=0.089$ and $A_{2}=0.773$ are the constants. 
However, when the two processes of opening and closing were distinguished, the $R^{2}$ of the two-variable models (either $R\left(Q_{\mathrm{p}}, D_{\mathrm{e}}\right)$ or $R\left(Q_{\mathrm{p}}, T_{\mathrm{L}}\right)$ ) for estimating $R D O$ showed a rather higher precision than that of the one-variable model $R\left(Q_{\mathrm{p}}\right)$ (Table 1). The regression formulas of $R\left(Q_{\mathrm{p}}, D_{\mathrm{e}}\right)$ and $R\left(Q_{\mathrm{p}}, T_{\mathrm{L}}\right)$ can be written into the following formulas:

$$
\begin{aligned}
R_{\mathrm{o}}\left(Q_{\mathrm{p}}, D_{\mathrm{e}}\right)= & \left(0.108+0.115 Q_{\mathrm{p}} / Q_{\mathrm{p}, \mathrm{Max}}\right) \\
& \left(-0.005+4.498 D_{\mathrm{e}} / D_{\mathrm{e}, \mathrm{Max}}\right) \\
R_{\mathrm{c}}\left(Q_{\mathrm{p}}, D_{\mathrm{e}}\right)= & \left(0.018+0.128 Q_{\mathrm{p}} / Q_{\mathrm{p}, \mathrm{Max}}\right) \\
& \left(5.292 \exp \left(0.109 D_{\mathrm{e}} / D_{\mathrm{e}, \mathrm{Max}}\right)\right) \\
R_{\mathrm{o}}\left(Q_{\mathrm{p}}, T_{\mathrm{L}}\right)= & \left(0.033+0.139 Q_{\mathrm{p}} / Q_{\mathrm{p}, \mathrm{Max}}\right) \\
& \left(0.001+5.384 T_{\mathrm{L}} / T_{\mathrm{L}, \mathrm{Max}}\right) \\
R_{\mathrm{c}}\left(Q_{\mathrm{p}}, T_{\mathrm{L}}\right)= & \left(0.031+0.207 Q_{\mathrm{p}} / Q_{\mathrm{p}, \mathrm{Max}}\right) \\
& \left(2.144 \exp \left(0.531 T_{\mathrm{L}} / T_{\mathrm{L}, \mathrm{Max}}\right)\right)
\end{aligned}
$$
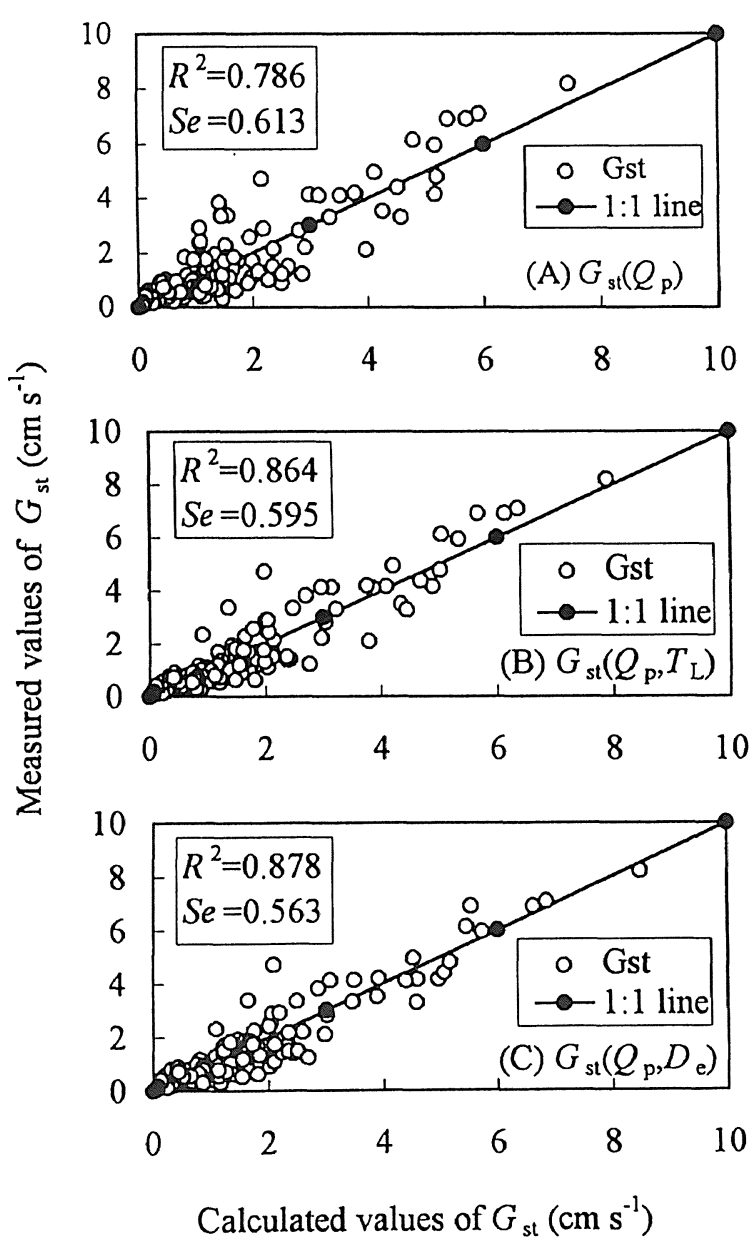

Fig. 2. Comparison of the measured value and the estimated value of stomatal conductance $\left(G_{\mathrm{st}}\right)$ from the model based equations (9), (10) and (11).

\subsection{Model for estimating $G_{\text {st }}$}

If formula (5) is combined with formulas (6), (7), (8), the combination model of equation (2) for estimating $G_{\text {st }}$ is constructed

$$
\begin{aligned}
G_{\mathrm{st}} & =G_{\mathrm{Max}} R\left(Q_{\mathrm{p}}\right) \\
G_{\mathrm{st}} & =G_{\mathrm{Max}} R\left(Q_{\mathrm{p}}, D_{\mathrm{e}}\right) \\
G_{\mathrm{st}} & =G_{\mathrm{Max}} R\left(Q_{\mathrm{p}}, T_{\mathrm{L}}\right)
\end{aligned}
$$

The estimated precision of these models is shown in Fig. 2. Although the estimated precision of $G_{\mathrm{st}}$ obtained with equations (10) and (11) are rather higher than that obtained with equation (9), from the point of view of simplicity, we think that equation (9) is better. In other words, a model for estimating stomatal conductance can be represented by

$$
G_{\mathrm{st}}=\frac{\left(A_{1}+A_{2} Q_{p} / Q_{p, M a x}\right)\left(d_{0}+d_{1} T_{L, m}+d_{2} T_{L, m}{ }^{2}\right)}{\left(b_{1}+b_{2} D_{e, m}\right)\left(1+c_{1}\left(-\psi_{L, m}\right)^{c 2}\right)}
$$

where $Q_{\mathrm{p}}$, and $Q_{\mathrm{p}, \mathrm{Max}}$ are the instantaneous and the maximum values of the photosynthetic photon flux density during daytime, and $T_{\mathrm{L}, \mathrm{m}}, D_{\mathrm{e}, \mathrm{m}}, \Psi_{\mathrm{L}, \mathrm{m}}$ are the daytime means of leaf temperature, saturation deficit and leaf water potential. The experimental coefficients in the equation are the same as those in formulas (5) and (6).

\section{References}

Jarvis, P. J., 1976: The interpretation of the variations in leaf water potential and stomatal conductance found in canopies in field. Philos. Trans. R. Soc. Lond. Ser. B. 273, 593-610.

Yu, G.-R., Nakayama, K., and Matsumura, H., 1996a: Comparison on variability of stomatal conductance between adaxial and abaxial surfaces of maize leaf. J. Agric. Meteorol., 52(2), 141148.

Yu, G.-R., Nakayama, K., Lu H.-Q., 1996b: Responses of stomatal conductance in field-grown maize leaves to certain environmental factors over a long term. J. Agric. Meteorol., 52(4), 311-320.

Yu, G.-R., Nakayama, K., Lu H.-Q., 1996c: Modeling stomatal conductance in maize leaves with certain environmental factors. J. Agric. Meteorol., 52(4), 321-330. 